\title{
Early Successful Orchidopexy Does Not Prevent From Developing Azoospermia
}

\author{
Faruk Hadziselimovic
}

Kindertagesklinik Liestal, Liestal, Switzerland

\begin{abstract}
Introduction: The incidence of Ad spermatogonia (stem cells for fertility) was assessed in 20 cryptorchid patients, all of whom had a successful orchidopexy in childhood but developed azoospermia following puberty.

Materials and Methods: From a cohort of 231 patients who had a semen analysis following successful orchidopexy 20 patients (9\%) had azoospermia. The patients were classified into 2 groups according to the time of surgery: $\mathrm{A}=<21$ months of age ( $\mathrm{n}=5$, mean $=10.7 \pm 8.6$ months $)$ and $\mathrm{B}=$ during childhood $(\mathrm{n}=15$, mean $=10.1 \pm 3$ years $)$. Nine of the 20 patients (45\%) had bilateral cryptorchidism: $\mathrm{A}=1$ and $\mathrm{B}=8$. Testicular biopsies were performed during orchidopexy and analyzed with semi-thin technique. The number of Ad spermatogonia and entire number of germ cells was determined. The patients' semen analyses were evaluated at least twice; FSH and testosterone plasma values were estimated.

Results: In group A, all patients had germ cells at the time of surgery (mean $=1.04 \pm 1.4$ germ cells per tubular cross section); only 6 patients in group B $(40 \%)$ had no germ cells (mean $=0.17 \pm 0.4)$; A vs. B, p $=0.0133$. Importantly, Ad spermatogonia were absent in the entire study population. The plasma FSH of 16 patients $(80 \%)$ was abnormal [median $=$ 16.35 IU/L (Interquartile range of sample - IQR 9.075-27.85 95\% CI, 3-53)] while the plasma testosterone of all the patients was normal.

Conclusions: The most severe cause of infertility in cryptorchid patients cannot be mitigated by an early successful surgery alone.
\end{abstract}

Key words: testis; cryptorchidism; surgery; germ cells; infertility; azoospermia

Int Braz J Urol. 2006; 32: 570-3

\section{INTRODUCTION}

Cryptorchidism is accountable for $8 \%$ of all sterile patients and for $20 \%$ of those with azoospermia (1). Cryptorchidism, therefore, is one of the most common etiology of secretory (non-obstructive) azoospermia. The clinical condition is more complex in that thirty-eight percent of azoospermic patients with germ cell aplasia that had other associated major medical illnesses, i.e., hypospadia, cryptorchidism as well as elevated serum FSH (2). We reported in an earlier study about the importance of Ad spermatogonia for insuring fertility in cryptorchidism (3). The incidence of Ad spermatogonia was assessed in 20 former cryptorchid patients, all of whom had a successful orchidopexy in childhood but developed secretory azoospermia following puberty.

\section{MATERIALS AND METHODS}

Nine percent (20/231) of patients that had a semen analysis following successful orchidopexy, 
developed azoospermia. During the surgery for undescended testis, testicular biopsies were performed, fixed in glutaraldehyde and embedded in Epon. Semi-thin sections $[1 \mu$ thick] were analyzed with a light microscope. The patients were classified into two groups according to the time of surgery: $A$ : $<21$ months of age $(n=5$, mean $=10.7 \pm 8.6$ months $)$ and $B$ : during childhood, $\mathrm{n}=15$ mean: $10.1 \pm 3$ years. Nine of the 20 patients (45\%) had bilateral cryptorchidism: $\mathrm{A}=1$ and $\mathrm{B}=8$. The number of Ad spermatogonia and entire number of germ cells was determined. The germ cell count was determined per tubular cross section analyzing the entire biopsy; at least 100 tubular cross-sections per biopsy. Semen analysis was performed with computer-aid and confirmed additionally with repeated microscopic examinations. At least, two semen analyses were analyzed. All patients had a comprehensive clinical examination, including a detailed history and physical examination. A total of 20 former cryptorchid patients had clinically non-obstructive azoospermia. Fifteen of the 20 patients were non-responders to HCG treatment before surgery. None of the patients at the time of the surgery had vas deferens obstructions or complete lack of the epididymis. The Wilcoxon-ManWhitney-U test was used for statistical analyses. The Institutional Review Board (IRB) approved all aspects of this study, according to the Helsinki declaration,.

\section{RESULTS}

Nine of the 20 patients (45\%) had bilateral cryptorchidism: one patient in Group A and eight patients in Group B. Both testes of all patients were located in the scrotum following puberty. Sperm count in all samples obtained was zero, confirming azoospermia. None of the patients had a completely atrophied orchidopexied testis. All patients in Group $\mathrm{A}$ at the time of surgery had testicular germ cells. However, the number (mean $=1.04 \pm 1.4$ ) was below the normal range for this age-group. Germ cells were absent in only 6 patients in Group B (40\%) at the time of the surgery; whenever present, the number of germ cells per tubular cross-section (mean = $0.17 \pm 0.4)$ was significantly lower if compared to Group A (patients with orchidopexy younger than
21 months of age). Ad spermatogonia were absent in the entire study population. Leydig cells of all patients were atrophic and their testicular interstitium was markedly collagenous. Plasma FSH was abnormal in $80 \%(16 / 20)$ of the patients, median value: 16.35 IU/L (IQR 9.075-27.85 95\% CI, 3-53) while plasma testosterone of all the patients was within the normal range (FSH: $2.1-5.5 \mathrm{IU} / \mathrm{L}, \mathrm{T}$ : 8.4-28.7 nmol/L).

\section{DISCUSSION}

Genetic abnormalities were present in $29 \%$ of a study population of 100 azoospermic men; azoospermia was induced in $22 \%$ of them by disease or an external influence. Cryptorchidism caused azoospermia in $27 \%$ of the population (4).Thus; cryptorchidism represents one of the most common etiologic factors of azoospermia.

Testicular malposition when untreated has a deleterious effect upon testicular development (5). Eighty-nine percent of patients with bilateral cryptorchidism who were untreated developed azoospermia, while azoospermia occurred in only $32 \%$ of those who responded successfully to hormonal [HCG] treatment and in $46 \%$ of those having had orchidopexy. However, no changes in the incidence of azoospermia $(13 \%)$ were found in unilateral cryptorchid patients regardless of the treatment modalities (5). This indicates that, at least, in unilateral cryptorchid patients, azoospermia is induced by factors unrelated to the malposition. One explanation for azoospermia could be the DAZ (deleted in azoospermia) gene alteration. The DAZ gene family on the Y-chromosome long arm is the major candidate for AZFc (azoospermia factor c) phenotype of male infertility, and it is expressed only in germ cells (6). The Sertoli cell function is not altered in patients with AZFc-DAZ deletions and a strong reduction of germ cells does not affect FSH-inhibin B feedback loop (6). However, microdeletion of Yq without differences in localization of deletion was evident in cryptorchid patients and in those with idiopathic infertility (7). Therefore, Yq microdeletion patterns do not elucidate clear differences in localization and extent of deletion between 
idiopathic and cryptorchid patients or between azoospermic and severely oligospermic. Furthermore, the incidence of such lesions varies considerably between $6.7-27.5 \%$ in unilateral ex cryptorchid patients (7).

An alternative explanation for inducing azoospermia is the absent transformation into Ad spermatogonia during mini-puberty (8). Ad spermatogonia are scarce in the first month of life; they increased markedly after 5 month of age paralleling the surge of gonadotrophins and testosterone (9). The number of Ad spermatogonia in the infant cryptorchid testes is low and there are distinctly fewer of them in the scrotal testes of unilateral cryptorchid infants compared to the control population (9). Our large fertility study showed no age related differences in the group of ex cryptorchid patients having defective germ cell development (no Ad spermatogonia) indicating that in these patients successful surgery is insufficient to prevent the development of infertility (10). One hundred and twenty two out of 231 (53\%) ex cryptorchid patients had no germ cells at the time of orchidopexy (10). Importance of testosterone for Ad spermatogonia development follows from study of patients with complete androgen insensitivity (11). In these patients, receptor failure is responsive for defective transformation of Ad spermatogonia which results in azoospermia development (11). In addition, thirty-five percent of all cryptorchid boys studied did not responded to HCG treatment (8). These data suggest that in nonresponders, Leydig cell insufficiency may affect the contralateral testes in some patients with unilateral cryptorchidism; importantly, the response is due to insufficient stimulation and it is not the direct consequence of malposition of the gonads. Thus, the transformation of gonocytes into Ad spermatogonia is gonadotrophin and T dependent (8). Therefore, an early developmental arrest of Ad spermatogonia induced through gonadotrophin deficiency can lead to azoospermia.

\section{CONCLUSIONS}

These observations underscore the importance of the development of Ad spermatogonia that takes place during mini-puberty. The non-obstructive azoospermia in cryptorchidism does not develop because of congenital lack or aplasia of germ cells, and the most severe form of infertility in cryptorchid patients cannot be prevented by an early successful orchidopexy.

\section{CONFLICT OF INTEREST}

None declared.

\section{REFERENCES}

1. David G, Bisson JP, Martin-Boyce A, Feneux, D: Sperm characteristics and fertility in previously cryptorchid adults. In: Job JCI (ed.), Cryptorchidism. Diagnosis and Treatment. Pediat. Adolesc. Endocr. 1979; 6: pp. 187.

2. Turek PJ, Kim M, Gilbaugh JH 3rd, Lipshultz LI: The clinical characteristics of 82 patients with Sertoli cellonly testis histology. Fertil Steril. 1995; 64: 1197-200.

3. Hadziselimovic F, Herzog B: The importance of both an early orchidopexy and germ cell maturation for fertility. Lancet. 2001; 358: 1156-7.

4. Fedder J, Cruger D, Oestergaard B, Petersen GB: Etiology of azoospermia in 100 consecutive nonvasectomized men. Fertil Steril. 2004; 82: 1463-5.

5. Hadziselimovic F, Herzog B: Importance of early postnatal germ cell maturation for fertility of cryptorchid males. Horm Res. 2001; 55: 6-10.

6. Foresta C, Bettella A, Moro E, Rossato M, Merico M, Garolla A, et al.: Inhibin B plasma concentrations in infertile patients with DAZ gene deletions treated with FSH. Eur J Endocrinol. 2002; 146: 801-6.

7. Foresta C, Moro E, Garolla A, Onisto M, Ferlin A: Y chromosome microdeletions in cryptorchidism and idiopathic infertility. J Clin Endocrinol Metab. 1999; 84: 3660-5.

8. Hadziselimovic F, Zivkovic D, Bica DT, Emmons LR: The importance of mini-puberty for fertility in cryptorchidism. J Urol. 2005; 174: 1536-9.

9. Hadziselimovic F, Emmons LR, Buser MW: A diminished postnatal surge of Ad spermatogonia in cryptorchid infants is additional evidence for hypogonadotropic hypogonadism. Swiss Med Wkly. 2004; 134: 381-4. 
10. Hadziselimovic F, Höcht B, Herzog B, Buser M: Infertility in cryptorchidism is linked to the stage of testicular development at orchydopexy. Swiss Med Wkly 2006;136 (Suppl 151) 41S.
11. Hadziselimovic F, Huff D: Gonadal differentiationnormal and abnormal testicular development. Adv Exp Med Biol. 2002; 511: 15-21.

Accepted after revision:

July 10, 2006

\section{Correspondence address:}

Dr. Faruk Hadziselimovic

KTK-Kindertagesklinik

Oristalstrasse $87 \mathrm{a}$

CH-4410 Liestal, Switzerland

E-mail: faruk@magnet.ch 